\title{
Ciudadanías emergentes: a propósito del posconflicto y la urgencia de una pedagogía para la paz desde la polifacética condición humana*
}

\section{Emerging citizens: apropos of post-conflict and urgency of a pedagogy for peace from the multifaceted human condition}

\author{
Gilberto Bonilla Sánchez \\ Magíster en Pedagogía \\ Universidad Santo Tomás Seccional Bucaramanga \\ Correo electrónico: gbonillasan@hotmail.com \\ Denix Alberto Rodríguez Torres \\ Doctor en Educación \\ Universidad Santo Tomás Seccional Bucaramanga \\ Correo electrónico: denixvirtual@gmail.com \\ Roberto Alonso Cardona Ospina \\ Magíster en Pedagogía \\ Universidad Santo Tomás Seccional Bucaramanga \\ Correo electrónico: roberto.cardona@ustabuca.edu.co
}

Recibido: 18 de enero 2016; aceptado: 6 de mayo de 2016

\section{Cómo citar este artículo:}

Bonilla, G., Rodríguez, D.A., y Cardona, R.A. (2016). Ciudadanías emergentes: a propósito del posconflicto y la urgencia de una pedagogía para la paz desde la polifacética condición humana. Espiral, Revista de Docencia e Investigación, 6(2), 37-52.

\section{Resumen}

Tipología textual y objetivo. El presente artículo de reflexión desarrolla un ejercicio teórico reflexivo originado en la línea de Democracia y Ciudadanía, perteneciente al grupo de Investigación en Desarrollo Humano del Departamento de Humanidades de la Universidad Santo Tomás Seccional Bucaramanga, reconocido por Colciencias en categoría B. Situados en Latinoamérica y en la singular realidad colombiana, se propone como objetivo desarrollar un horizonte teórico que contribuya a enriquecer los referentes epistémicos que piensan las ciudadanías emergentes que suponen ahora las nuevas formas de ser y estar en sociedad.

Metodología. Se abordan dos componentes: en primer lugar una invitación a mirar distinto el fenómeno de la violencia, más allá del horror que generan los grupos armados, desde un enfoque que favorece una mirada esperanzadora. Y por otra parte, se plantea la urgencia de reconocer las nuevas ciudadanías para involucrarlas en el trabajo por una cultura de la paz, una cultura de la no violencia, que devuelva la esperanza de pensar una sociedad donde podamos convivir los distintos, respetando y defendiendo la Vida.

Resultados. Esta reflexión teórica no es concluyente, porque, como educadores, entendemos el compromiso y la necesidad de ayudar a pensar acciones y opciones desde el posconflicto colombiano; por ello, desde una pedagogía para la paz, se reconoce la necesidad de considerar la complejidad y las polifacéticas manifestaciones de la condición humana en las dinámicas que piensan los nuevos roles sociales.

Palabras clave: Ciudadanía emergente, condición humana, pedagogía, paz, posconflicto. 


\section{Abstract}

Tipología textual y objetivo. This article develops a reflexive theoretical exercise originated in the line of Democracy and Citizenship, belonging to the Human Development Research group of the Department of Humanities of the Santo Tomás University of Bucaramanga, recognized by Colciencias in category $B$.

Located in Latin America and in the unique Colombian reality, it aims to develop a theoretical horizon that contributes to enrich the epistemic referents that think the emerging citizenships that now suppose the new ways of being and being in society.

Methodology. Two components are addressed: first, an invitation to look at the phenomenon of violence, beyond the horror generated by armed groups from an approach that favors a hopeful look. And, on the other hand, the urgent need to recognize the new citizenships to involve them in work for a culture of peace, a culture of nonviolence, to return the hope of thinking to a society where we can live together, respecting and defending life.

Results. This theoretical reflection is not conclusive because, as educators, we understand the commitment and the need to help people to think actions and options for the Colombian post conflict; for this reason, from a pedagogy for peace, the need to consider the complexity and multifaceted manifestations of the human condition in the dynamics of the new social roles is recognized.

Keywords: Emerging citizenship, human condition, post - conflct.

\section{Introducción}

Tanto las violencias como los conflictos y, en ellas, las dinámicas de la guerra son expresiones humanas que, desde la educación y los escenarios pedagógicos, requieren mirarse no solamente como una tragedia sino como una oportunidad de aprendizaje, como una experiencia humana, política, ética y social que requiere un enfoque integrador para pensar otros escenarios posibles, otras opciones humanas más allá del uso de la violencia y del terror.

Desde la óptica de una pedagogía para la convivencia respetuosa del otro (otro como naturaleza y como individuo, otro como lo que es distinto a mí) resulta significativo integrar lo que advierte Nussbaum cuando invita a imaginar la experiencia del otro, a entender otros mundos de vida y las miradas y opciones que en ellos se tienen lo que significaría para nuestra cultura abandonar los egocentrismos y dejar de pensarnos como salvadores o redentores de una sociedad que ni empezó ni va a terminar con el aporte que hacemos a nivel individual.

En un contexto de violencia y desangre, como lo es el caso colombiano conviene conocer los argumentos que esgrime Nussbaum al considerar las emociones como manifestaciones del animal político, de los seres racionales, por ello en la obra de 2014, Emociones políticas, ¿Por qué el amor es importante para la justicia? Sostiene que el amor es el elemento fundamental para lograr y mantener una sociedad liberal decente. Cómo le vendría de bien a nuestros pueblos latinoamericanos, y a Colombia, apoyarse de asesores filosóficos, como de la estudiosa de las emociones humanas Martha Nussbaum o del experto en cultura ciudadana Antanas Mockus (1999).

Si cada ser humano entendiera que ni el mundo empieza cuando nació ni termina cuando muere, quizá la convivencia social sería más respetuosa del otro. Los adanes (complejo de Adán) le hacen mucho daño a la convivencia, porque se creen destinados para una misión especial, consideran que viene a salvar a la humanidad, o a Colombia. El profesor Antanas Mockus (1999) a través de su valioso aporte pedagógico y político demostró que en Colombia es posible construir una cultura ciudadana que respete la diferencia y aprenda que la vida es sagrada, que el otro es sagrado, que los recursos públicos son sagrados, que ningún individuo debe considerarse ni más ni menos que nadie. Por ahí se abre el camino de una pedagogía para la paz, el posconflicto y la convivencia desde las poliformas de la condición humana'.

1 La categoría Condición Humana se contempla desde el aporte de Arendt $\mathrm{H}$. y su desarrollo se puede conocer en Bonilla, Cardona, Rodríguez (2015). 


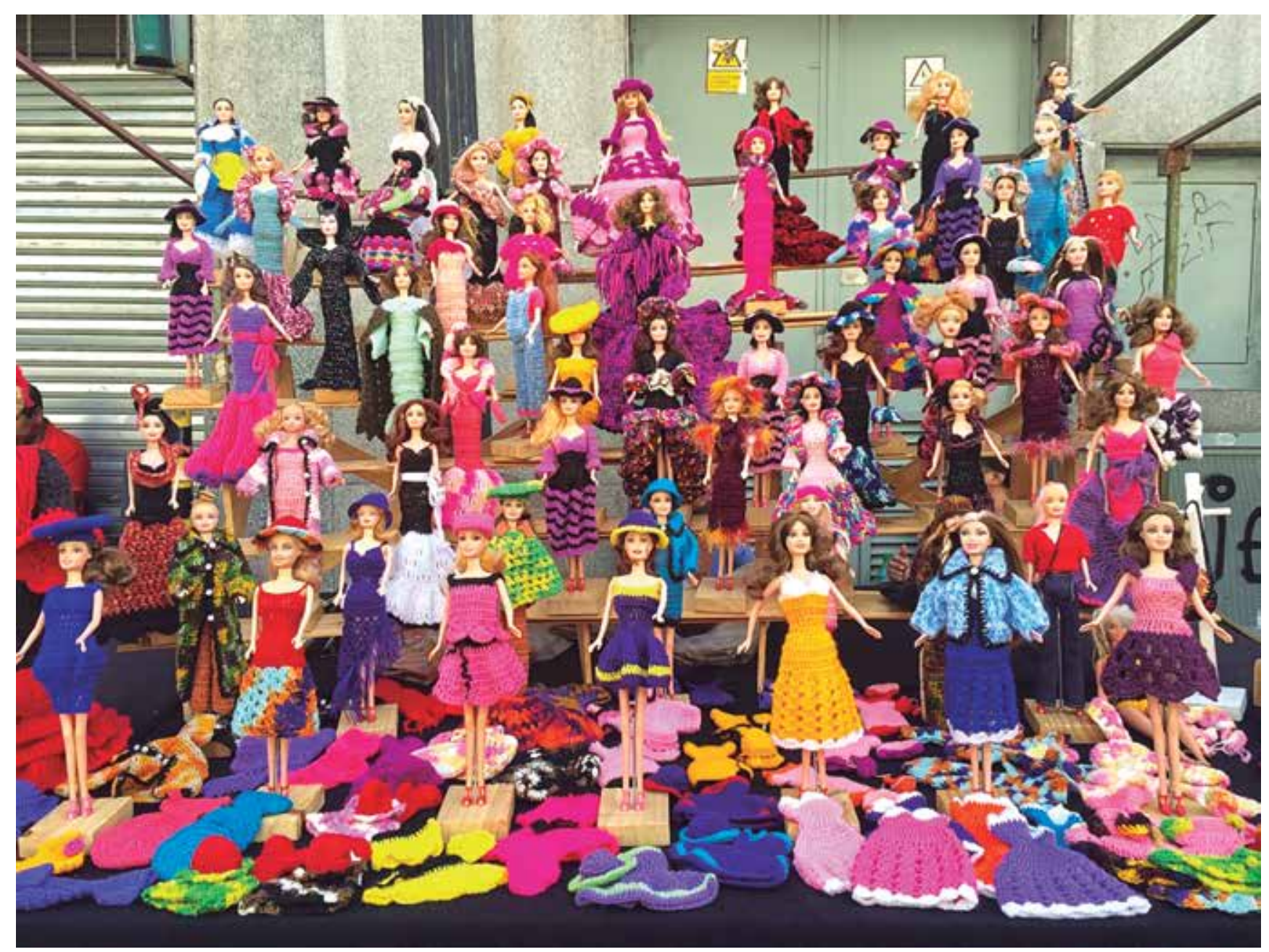

\section{Desarrollo: mirar distinto la violencia colombiana, la esperanza posible}

En una historia como la latinoamericana, y la colombiana donde la violencia y el odio colonizaron, se requiere una pedagogía para la paz, que conlleva una acción de perdón, para desprendernos del carácter violento, que odia, que atemoriza, que intimida, y acogernos al carácter comprensivo que incluye, respeta, valora, defiende y asimila al otro como un distinto y un complemento en el gran concierto vital; como bien lo sugiere el escritor Mario Mendoza:

odiar va creando, además, una personalidad narcisista que se va anclando cada vez con mayor fuerza en el yo. Lo único importante es lo que me sucede a mí. Yo soy el centro del mundo. Yo tengo la razón. Nadie se da cuenta de la verdad, excepto yo. Nadie ha sufrido como yo. Las consecuencias físicas y mentales de ese exceso de presencia en sí mismo son muy negativas. El sujeto no puede expandirse, explayarse, compartir, enriquecerse con las experiencias de los otros. Es un círculo vicioso que se retroalimenta cada día. Odiar debilita mucho (2014, p. 271).

Una sociedad como la colombiana, con más de cincuenta años de un conflicto armado, con una guerra fratricida que deja muertos de lado y lado, en un enfrentamiento entre grupos armados, incluida la fuerza estatal, cae en una situación de incertidumbre y no se confía en el fin del conflicto. Además de la desconfianza que genera la guerra, también aparecen los intereses de los guerreristas, las conveniencias y las ventajas que trae para muchas personas $y$ organizaciones perpetuar el negocio de las armas y todo lo que demanda la guerra. 
La sociedad inmersa en una guerra histórica, que condena a sus hijos a vivir en medio de las balas, con los ruidos de la violencia como música de fondo, tiene paradojas como las que muestran a nuestro país como uno de los más felices del mundo. Y claro, es que una de las formas de contrarrestar tanta atrocidad es el humor, que permite reírnos hasta de lo más doloroso, se podría decir que Colombia sobrevive gracias a su buen sentido del humor. Quizá por eso el pensador oriental Bhagwan (1995) le da tanto protagonismo a la acción de reír y al sentido del humor:

El sentido del humor es una de las cosas más esenciales de la inteligencia. En el momento en que lo pierdes, perderás también la inteligencia; cuánto más sentido del humor tengas, más inteligente serás. La sociedad enseña el control sobre ti mismo y el sentido del humor significa relajación (p. 102). Mi definición del hombre es que es un animal que ríe (p. 105).

Algunos la conciben como una sociedad creativa para sobrevivir a la adversidad, recursivos y dados a salir bien librados del barro y la putrefacción social. Lo cierto es que aquí estamos hace mucho rato en un todos contra todos, los que creen en determinada deidad contra los que creen en otra o contra los que no creen; los que le hacen fuerza a un equipo de fútbol contra los de otros equipos o contra los que no son seguidores deportivos; los politiqueros corruptos contra los ciudadanos críticos y reflexivos; los patronos negándoles a los empleados mejores condiciones laborales; los de este sector contra los otros, porque aquí cuenta mucho el apellido, el estrato y el "linaje"; por ello con todo y recursividad aquí estamos en un enfrentamiento bárbaro de sálvese quien puede, "estamos en una batalla de todos contra todos" (Mendoza, 2014, p. 269). Y como bien lo enfatiza Mendoza, "no hay democracia participativa auténtica sin una conciencia del cuerpo propio y de los otros" (p. 288). Es así que:
La peor violencia no es la violencia política, es decir, la que viene de fuera del sistema. En nuestro caso, la de la guerrilla, los paramilitares o el narcotráfico. No le vamos tampoco a restar importancia. Es una violencia que nos ha hecho mucho daño y que ha terminado con vidas valiosas, qué duda cabe. Pero no es la peor ni la más dañina. La peor violencia se está cocinando al interior del mismo establecimiento, aquí y ahora, entre nosotros mismos. Por probabilidades, estamos más cerca de ser agredidos por nuestro jefe en el trabajo que por las Farc. Estamos más cerca de ser violentados por nuestros padres en nuestra casa que por Al Qaeda. En el caso de las mujeres, están más cerca de ser maltratadas física o psicológicamente por un hombre del común (un novio, un amigo, un primo, un desconocido) que por un grupo terrorista (Mendoza, 2014, p. 269).

En consonancia con los argumentos de Mendoza, que se destaca por narrar la laberíntica condición humana urbana, está el aporte del escritor William Ospina quien invita, también, a pensar en el fenómeno de la violencia más allá de los grupos armados,

Y ¿qué se podía esperar de una historia en la que miles de seres quedaron al margen de todo proyecto de civilización, de todo esfuerzo de inclusión, de todo proceso educativo y cultural? Nada como una sociedad que expulsa y que desampara, que priva a los seres humanos de ternura y de dignidad, para engendrar monstruos (Ospina, 2013, p. 101).

Colombia también tiene el vergonzoso record de los asesinos en serie más peligrosos como lo investigó y documentó el antropólogo Cruz Niño (2013) en Los monstruos en Colombia sí existen. Las historias que contaban los abuelos a los niños también estaban plagadas de terror; la oralidad, que era la manera de contar e invitar a conservar las tradiciones, también se daba desde las anécdotas duras y descarnadas, desde los relatos de una convivencia atravesada por la violencia, "Lo que pasaba es que mataban a la gente. Despescuezaban a todos los que se quedaban en esa choza" (p. 20). 


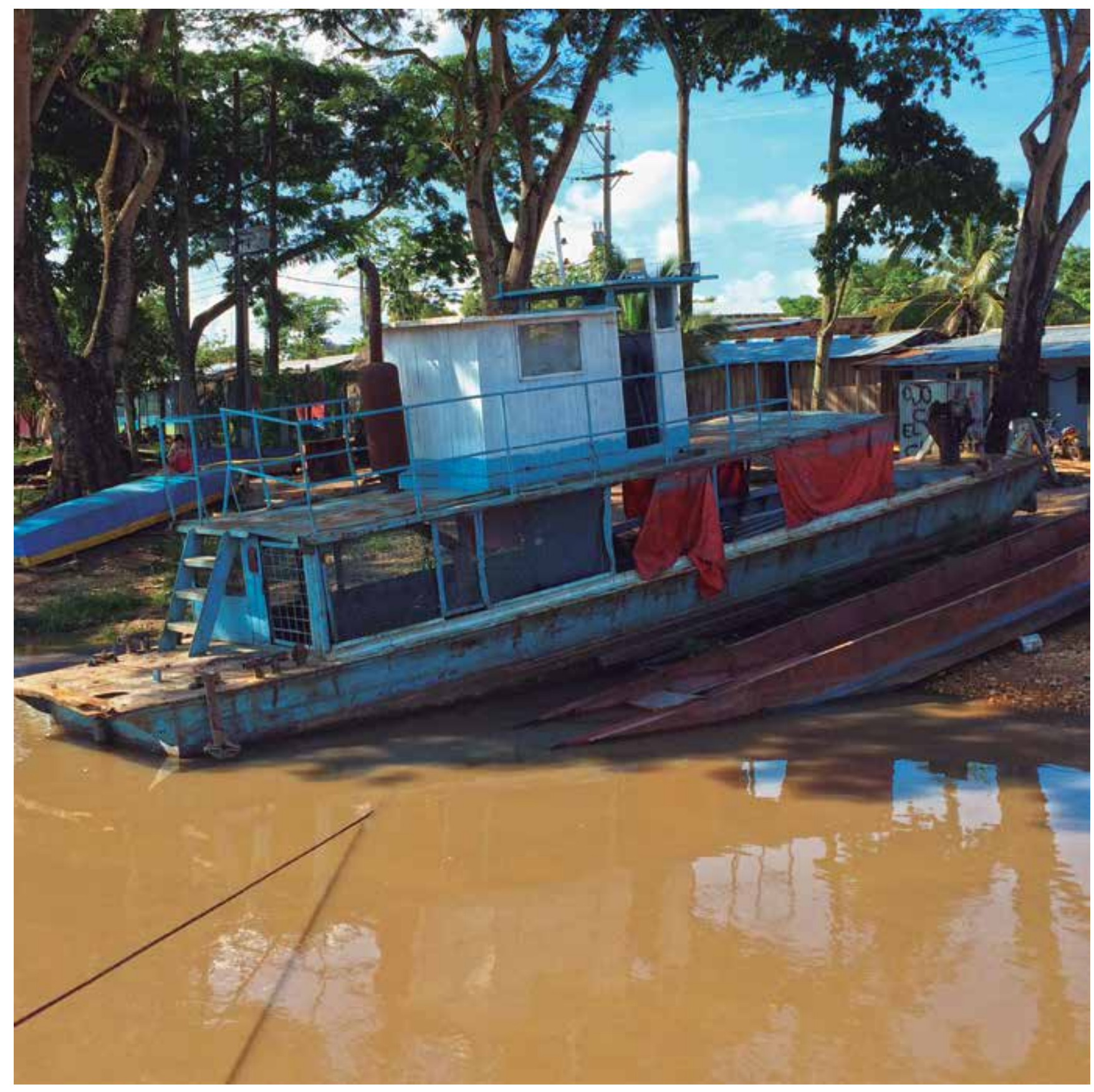

Ahora pienso que el miedo que me causó el cuento está relacionado con la verosimilitud de la narración. No se trataba de fantasmas o brujas, no eran la Madremonte y la Llorona; se trataba de un peligro real, de la existencia de seres de carne y hueso que asesinan y matan sin piedad, de monstruos humanos, de sádicos que pueden estar en cualquier lugar, maquinando y esperando una oportunidad para acabar con la vida de algún inocente (p. 21).
Es paradójico cómo nos venden la violencia, esa sí la incluyen en la canasta familiar y nos ponen a pensar que son los otros los que nos violentan y por ello nos cuesta tanto reconocer que la violencia está con nosotros, en cada uno, en los ambientes cotidianos y los círculos que frecuentamos, la violencia armada y quizá terrorista es muy dañina y marcó la historia, pero la otra, la doméstica, sigue afectando el día a día 
la violencia laboral, la violencia contra los menores de edad, la violencia de género, el racismo, la segregación social, el arribismo, el desprecio, el matoneo escolar, el desdén por el otro, el terrorismo de Estado, la violencia de la moda y la publicidad (que genera millones de personas anoréxicas, bulímicas y con trastornos de alimentación), el terrorismo económico y bancario son formas eficaces de microviolencia que están convirtiendo la convivencia de las grandes ciudades en un infierno (Mendoza, 2014, p. 268).

Pero sin menospreciar la maldita violencia armada, que en nuestro país hasta cumple bodas de oro, es necesario que desde la academia también se visibilice y reflexione sobre la condición humana y el carácter violento del proyecto humano, en particular en un contexto como el nuestro. De la mano de Ospina es importante reconocer que

Desde hace medio siglo, Colombia vive uno de los conflictos políticos más dramáticos del hemisferio occidental, con cientos de miles de muertos, millones de víctimas y de refugiados internos, millones de migrantes a otros países y un creciente deterioro del orden institucional que se puede medir por la crisis de la justicia, los niveles escandalosos de corrupción, el número de congresistas y gobernantes que pasan directamente del poder a la celda, los índices de pobreza y de miseria, la inseguridad, la delincuencia, el atraso de la infraestructura y la incapacidad de convertir la indudable riqueza del territorio en algo que beneficie a las mayorías y garantice la prosperidad general (Ospina, 2013, p. 7).

Muy en consonancia con la propuesta de liberalismo político que trabaja Nussbaum, a partir del cultivo de las emociones, está el aporte de Ospina:

Es imposible exagerar la importancia de estas cosas invisibles, de la lealtad, del amor por el territorio, del orgullo por los conciudadanos, de la solidaridad, de la confianza, de la responsabilidad, de la conciencia de sentirse aceptado y dignificado, en la construcción de una sociedad verdadera. Por eso también son hechos políticos fundamentales el afecto, el orgullo, la dignidad, el respeto, la compasión, la memoria comparti- $\mathrm{da}$, el amor que se convierte en generosidad, en confianza y en convivencia (2013, p. 174).

La educación necesita trabajar las emociones e implementar en los planes de estudio sentimientos como la compasión, la cooperación, el cuidado de sí y del otro, el sentido de corresponsabilidad; implementar o fortalecer estos componentes educativos,

para ello es indispensable transformar una lengua que se ha utilizado por siglos para someter y para despojar, para negar los valores colectivos, en un instrumento expresivo de la emoción y del afecto, en un poder que de verdad ayude a descifrar la realidad y que también ayude a transformarla (Ospina, 2013, p. 175).

Una educación que promueve la compasión y la cooperación ayuda a superar años de guerra y horror. En Colombia, los intentos por desmontar los grupos armados no son pocos, la búsqueda de la paz ha sido el caballito de batalla de los últimos presidentes y de buena parte de los políticos, aunque otros precisamente han cabalgado sobre este asunto para invitar a terminar la guerra guerreando, combatiendo, matando. En el gobierno del presidente Betancur (1982 - 1986) se llegó al punto de conformar una Comisión de Violentólogos para estudiar las distintas facetas de la violencia,

Pero a los violentólogos les faltó establecer con claridad que todas las violencias tenían un mismo origen que era tanto la explotación de los trabajadores por los dueños de las tierras, del ganado, de las fábricas, de las minas y de las empresas económicas, como la falta de libertades, de representatividad, de participación, de justicia; en últimas, la ausencia de un sistema verdaderamente democrático.

En esos días, Eduardo Galeano se preguntaba si los colombianos son violentos por naturaleza, si es "gente de gatillo alegre que los violentólogos deberían estudiar al microscopio", o si la violencia es más bien "la hija del desprecio y la desesperación". Decía también que las contradicciones sociales en Colombia, donde los ricos son inmensamente ricos, y los pobres son "pobrísi- 
mos", son más explosivas que todas las bombas que alguna vez estallaron en Medellín.

Betancur quiso dialogar con la insurgencia, a la que por primera vez se reconoció como fuerza política. Ya era hora de que alguien tomara en serio el conflicto interno. Pero el Gobierno gringo, las fuerzas armadas colombianas y las clases dominantes pusieron el grito en el cielo y presionaron a Belisario para evitar que hiciera concesiones a la izquierda (Claux, 2011, p. 242).

Mario Mendoza, el cronista del drama humano y de los laberintos que se construyen en nuestra sociedad subterránea, el narrador de esa sociedad que no se hace visible a simple vista, denuncia a través de sus obras cómo

la guerra ha sido tan devastadora, tan cruenta, tan llena de trampas y mentiras, que nos ha obligado a concentrarnos en ella y sus horrores. Y esa guerra tiene varias aristas: gobiernos corruptos atravesados por asesinos y por políticos al servicio de mafias secretas, guerrilleros conformando carteles de traficantes de drogas y secuestrando a los ciudadanos a diestra y siniestra, paramilitares genocidas obsesionados con la sangre y el exterminio, capos sicarios, torturadores, víctimas por todas partes y en todos los estratos sociales" (Mendoza, 2014, p. 9).

Aquí evidencia Mendoza que la guerra se perpetúa por el negocio tan lucrativo que ella misma representa, la guerra hace parte de un negocio boyante que enriquece a los dueños y deja muertos a unas víctimas que la tienen como fuente de empleo.

Por ello invita Mendoza a pensar la complejidad humana más allá de la violencia armada,

Quizá si dejamos de hablar tanto sobre la guerra los mismos guerreros se sientan menos protagónicos y cambien de oficio. Quizá negarnos a escribir sobre ellos sea una forma de demostrarles que no tiene el control. Quizá si empezamos a soñar con otros asuntos desarticulemos la guerra y seamos capaces de abrir nuevos espacios para nuestra cotidianidad (Mendoza, 2014, p. 10).
Aquí hay una invitación a pensar en la esperanza, en la cooperación, en la humanidad terrenal, en la ética del género humano más allá de la visibilización del solo conflicto armado.

Porque el conflicto no afecta solamente a las personas, esta situación de violencia maltrata, hiere, afecta y mata la vida en su más amplia concepción. La naturaleza, toda, gime por los sufrimientos de la devastadora violencia, la vida cósmica se afecta con la interrupción violenta y el freno inesperado del ciclo vital. Por ello urge pensar una nueva ética, una postura más allá de lo antropológico, integrando la vida en su dimensión más amplia, como bien lo invita el profesor Marco Raúl Mejía:

avanzar hacia un geocentrismo en donde la vida, en cualquiera de sus formas, está en el centro del escenario. Equivale a entender la vida humana como parte integral de las condiciones globales de la vida en el planeta y dentro de las condiciones posibles de la existencia en el futuro. En este sentido, es imperativo no sólo la reflexión y configuración de nuevos deberes y derechos sino además, el replanteamiento necesario para colocar el lugar de lo humano en esos nuevos deberes y derechos (Mejía, 2006, p. 60).

Porque la dinámica vida social implica que nuevas formas de ciudadanía emergen y nuevos retos traen a la vivencia y convivencia entre humanos y en la vida cósmica en general.

Además de reconocer la histórica guerra y los múltiples desafíos del posconflicto, la superación de la violencia implica a los diferentes agentes educativos -maestros- y la sociedad en general para ayudar a pensar la convivencia respetuosa de la vida, en equilibrio y armonía, donde se parta de una regulación ética que responda a los desafíos actuales,

una mirada diferente sobre el desarrollo social, tendrá que configurar otros valores que hablen de justicia, equidad social, sanidad ambiental, realización humana y de una construcción estética del mundo. Esto significa dar vuelta a la concepción de un ser humano dueño de la tierra y 
controlador de la naturaleza para avanzar hacia la visión de un mundo donde la vida sea cuidada en sus múltiples formas, lo que supone reconocer la conflictividad de la relación entre lo artificial, la naturaleza y lo humano (Mejía, 2006, p. 62).

Ya en el 2001 el gran amigo de Latinoamérica y de Colombia, el francés Edgar Morin, invitaba a pensarnos como una sociedad distinta y distante de la violencia,

Vuestro país no debe ignorar que es del fondo del abismo que puede salir la regeneración y la resurrección. Pienso que la guerra no es tanto la guerra de las personas, es la guerra de ideas locas, es la guerra ante las incomprensiones, es la guerra ante los monoteísmos, es la guerra ante las intolerancias; y pienso que se necesita, para ayu$\mathrm{da}$, recordar las palabras de Pascal que dicen: El contrario de una verdad no es un error, es una verdad contraria. Comprender que cada una tiene su verdad y entender qué significa cuál puede ser el valor de esta verdad. Hoy para mí es el principio de un nuevo abrazo; abrazar es el modo corporal de manifestar al otro, no únicamente su simpatía sino su comprensión, abrazar ayuda al otro a su comprensión (Memorias, 2001, p. 20).

En este sentido Morin invita a pensar una ética de la comprensión,

Sin simpatía, sin amistad, no hay comprensión. La misión de un pensamiento complejo no es una misión únicamente cognitiva. Es también una misión ética en sí misma, porque si el pensamiento complejo quiere religar las cosas separadas, quiere comprender las realidades, quiere escapar a este modo de conocimiento que fragmenta y separa todo; y quiere demostrar que hay un tejido común a las cosas que parecen separadas, entonces esta misión cognitiva de la solidaridad de hecho ante las cosas se prolonga naturalmente hacia una solidaridad con los otros humanos; y también, se puede pensar que se extienda hacia una sociedad muy compleja, una sociedad donde existan muchas libertades, muchas singularidades, mucha posibilidad de eventualidades, de creatividad y de equivocaciones; posibilidades de error y de peligro. No es una sociedad perfecta pero sí una sociedad que da libertad" (Memorias, 2001, p. 20).
Es la esperanza la que le da sentido a la vida, sin esperanza la existencia no se hace humana, sin esperar no se vive, la vida espera siempre un día nuevo y distinto, un día en que pueda caminar, una oportunidad para volar, un momento para pensar, una ocasión para marchar, un instante para respirar, una plenitud para avanzar. Esperar es humanizar la existencia, por eso esperar es de humanos. Invitados a una esperanza de vida que permita hacerle una jugada a la muerte temprana, a la muerte asesina, a la parca que violenta, para que en Colombia, en Latinoamérica y en el planeta las personas puedan morir de viejos, y haya una segunda oportunidad en este Macondo real.

\section{Y precisa Morin:}

Nosotros estamos tres en uno, individuo parte de una sociedad, parte de una especie. Estos tres rasgos son inseparables y cada uno produce los otros, pero significa para la ética que hay tres direcciones de la ética, que puede ser contradictoria en algunos momentos. Una dirección de la ética personal, individual por su compromiso, su honor; una ética al servicio de la sociedad y que se puede hacer contra la sociedad, se pone al servicio de los individuos, es decir una sociedad democrática, una ética al servicio del ser humano (Memorias, 2001, p. 354).

De una manera muy amigable y cercana el francés Morin habla de nuestra situación sociocultural, de la realidad que necesita pensarse y reestructurarse a favor de la vida y de la esperanza de una vida con opciones distintas,

En vuestro país, Colombia, hay un divorcio gigante. Por un lado, una vitalidad intelectual, un montón de buenas voluntades, posibilidades geniales de un país tan rico por su diversidad, su mestizaje, ético y cultural. Me parece que no conozco un país que tenga tantas posibilidades. Esa es una de las razones por la que cada vez me siento más íntimamente, no puedo decir que soy ciudadano de vuestro país, pero digamos casi ciudadano. Hay todas esas posibilidades, todas esas riquezas; y por otro lado el desencadenamiento destructor y loco de las violencias. 
Es en una guerra que conduce a la desintegración de una maravillosa nación. Es una lucha terrible, gigante, entre fuerzas de vida y fuerzas de muerte, fuerzas de degeneración y fuerzas de destrucción. Ustedes deben saberlo, ustedes son los protagonistas adelantados de las fuerzas de vida. Pero no basta lo que se requiere es el pensamiento complejo. Hay otra cosa que comprende muy bien el pensamiento complejo: Es el amor, es sobre todo el amor a su patria: Estoy convencido que si todos tienen en la mente el amor por su patria es una vía para la reconciliación y la paz. Entonces, tenerlo con vosotros debe permitir saber dónde están los elementos, los más ricos de la generación de Colombia. Adelante en los caminos que se hacen al andar (Memorias, 2001, p. 355).

Las conversaciones de paz necesitan dar un giro importante porque los colombianos estamos en deuda con los coterráneos, se necesita hacer procesos de inclusión respetuosa con las comunidades indígenas, con la población infantil, con los habitantes de la calle, con la tercera edad, con las mujeres cabeza de familia y las madres solteras, con los niños y las niñas, con la población desplazada y desarraigada de sus territorios culturales, costumbres y modos de vida, con la población discapacitada o en estado de indefensión, con los enfermos, con los estudiantes, con los empleados, los desempleados, los asalariados, con las minorías y con los marginados sociales. Pero también con el medio ambiente y los recursos naturales, con la riqueza hídrica, con la biodiversidad de flora y fauna, oler el aroma de nuestras flores y escuchar la música de la naturaleza que convive respetando la vida diversa. Es una tradición histórica que necesita repensarse, como bien lo invita Morin:

Es en este reencuentro con el pasado que un grupo humano encuentra la energía para enfrentar su presente y preparar su futuro. La búsqueda de un mejor avenir debe ser complementaria y no antagonista con los reencuentros en el pasado. Todo ser humano, toda colectividad debe dirigir su vida en una circulación interminable entre su pasado donde encuentra su identidad apegándose a sus ascendentes, su presente donde afirma sus necesidades y un futuro hacia donde proyecta sus aspiraciones y sus esfuerzos (2001, p. 80).

Y terminando con la reflexión que hace el padre del pensamiento complejo, Edgar Morin, hay que reconocer que "no podemos esperar el mejor de los mundos, pero sí un mundo mejor" (Morin, 2011, p. 283). Los países, y las personas que han sufrido el horror de la guerra necesitan pasar por reformas solidarias,

no sólo institucionales, económicas y sociales, también son mentales, y requieren una aptitud para concebir y abarcar los problemas globales y fundamentales, una aptitud que, a su vez precisa de una reforma de la mente. La reforma de la mente depende de la reforma educativa, pero ésta también depende de una reforma del pensamiento: son dos reformas clave, indispensables ambas para una reforma del pensamiento político que dirigirá, a su vez, las reformas sociales, económicas, etc. (Morin, 2011, p. 283).

La única reforma no es la que combate, o dialoga con los grupos armados, ni la que busca silenciar los fusiles, hay otras reformas que socialmente urgen, en especial la que ayude a pensar una educación más incluyente, respetuosa de la diferencia participativa y democrática, menos plutócrata y más académica, una educación que permita el disenso y el pensamiento divergente. Una educación que permita pensar la esperanza humana como paradigma de dignificación de la vida, la vida que siempre espera un nuevo amanecer. Un entramado de situaciones que implican pensar en conjunto.

Pero la reforma de la educación también depende de la reforma política y de las reformas de la sociedad, que derivan de la restauración del espíritu de responsabilidad y de solidaridad, producto de la reforma de la mente, de la ética, de la vida. Cada reforma se alimentaría, por lo tanto, de todas las demás. Existe, pues, un círculo virtuoso entre todas las reformas, que dependerían unas de otras y estimularían recíprocamente (Morin, 2011, p. 284). 
Ya renglón seguido invita Morin a mantener viva la esperanza, a esperar en que un mundo y una sociedad distinta son posibles

La esperanza parece muerta. Las viejas generaciones están desengañadas por falsas promesas y falsas esperanzas. Las jóvenes generaciones están desnortadas. Se quejan de que ya no haya ninguna causa por la que luchar. Hoy, la causa es inequívoca, sublime: se trata nada más y nada menos que de salvar a la humanidad (Morin, 2011, p. 285).

Porque la vida es esperanza, esa que promulga Erich Fromm desde La revolución de la esperanza (1966) o Paulo Freire desde la Pedagogía de la esperanza (2007), que necesita defensores y pedagogos, educadores comprometidos con la educabilidad humana en una sociedad herida a muerte que se inca en una actitud esperanzadora,

La esperanza ha resucitado en el corazón mismo de la desesperación. Esperanza no es sinónimo de ilusión. La esperanza verdadera sabe que no es certidumbre, pero sabe, como dijo el poeta Machado, que se hace camino al andar; sabe que la salvación a través de la metamorfosis, aunque improbable, no es imposible (Morin, 2011, p. 285).

Ante tanta desconfianza y suspicacias guerreristas es bueno recordar, desde Morin, y los Siete saberes necesarios para la educación del futuro, que

la ética de la comprensión es un arte de vivir que nos pide, en primer lugar, comprender de manera desinteresada. Pide un gran esfuerzo ya que no puede esperar ninguna reciprocidad: aquel que está amenazado de muerte por un fanático comprende por qué el fanático quiere matarlo, sabiendo que éste no lo comprenderá jamás. Comprender al fanático que es incapaz de comprendernos, es comprender las raíces, las formas y las manifestaciones del fanatismo humano. Es comprender por qué y cómo se odia o se desprecia. La ética de la comprensión nos pide comprender la incomprensión (Morin, 2001, p. 104).
La pedagogía para la paz empieza por la pedagogía de la ética, el reconocer que la vida es sagrada y que el otro tiene tanto derecho a existir como individuo, como realidad particular, porque

La ética de la comprensión pide argumentar y refutar en vez de excomulgar y anatemizar. Encerrar en la noción de traidor aquello que proviene de una inteligibilidad más amplia impide reconocer el error, el extravío, las ideologías, los desvíos (Morin, 2001, p. 104).

Por ello argumenta el padre del Paradigma de la Complejidad:

La comprensión no excusa ni acusa: ella nos pide evitar la condena perentoria, irremediable, como si uno mismo no hubiera conocido nunca la flaqueza ni hubiera cometido errores. Si sabemos comprender antes de condenar estaremos en la vía de la humanización de las relaciones humanas (Morin, 2001, p. 104).

Desde la academia, las aulas, los grupos de investigación, las publicaciones, los eventos de divulgación y los múltiples escenarios sociales, se necesita promover una actitud esperanzadora, una apuesta por la vida y por la dignificación de la existencia que no se reduzca únicamente a lo humano.

\section{Urgencia de una ciudadanía emergente para una esperanza de paz}

La ciudadanía y sus múltiples formas de ejercerla han sido el tema central de análisis y discusiones que permiten comprender su desarrollo y evolución en las distintas épocas de la historia del hombre. Reflexiones que inician en la polis griega y finalizan con el tipo de ciudadano que construye a conveniencia el Estado-Nación de la actualidad, así como estudios para diferenciar tipologías o enfoques teóricos de la ciudadanía abordados en los diferentes contextos de su aplicación, como lo son las ciudadanías promovidas por el liberalismo, el comunitarismo, 


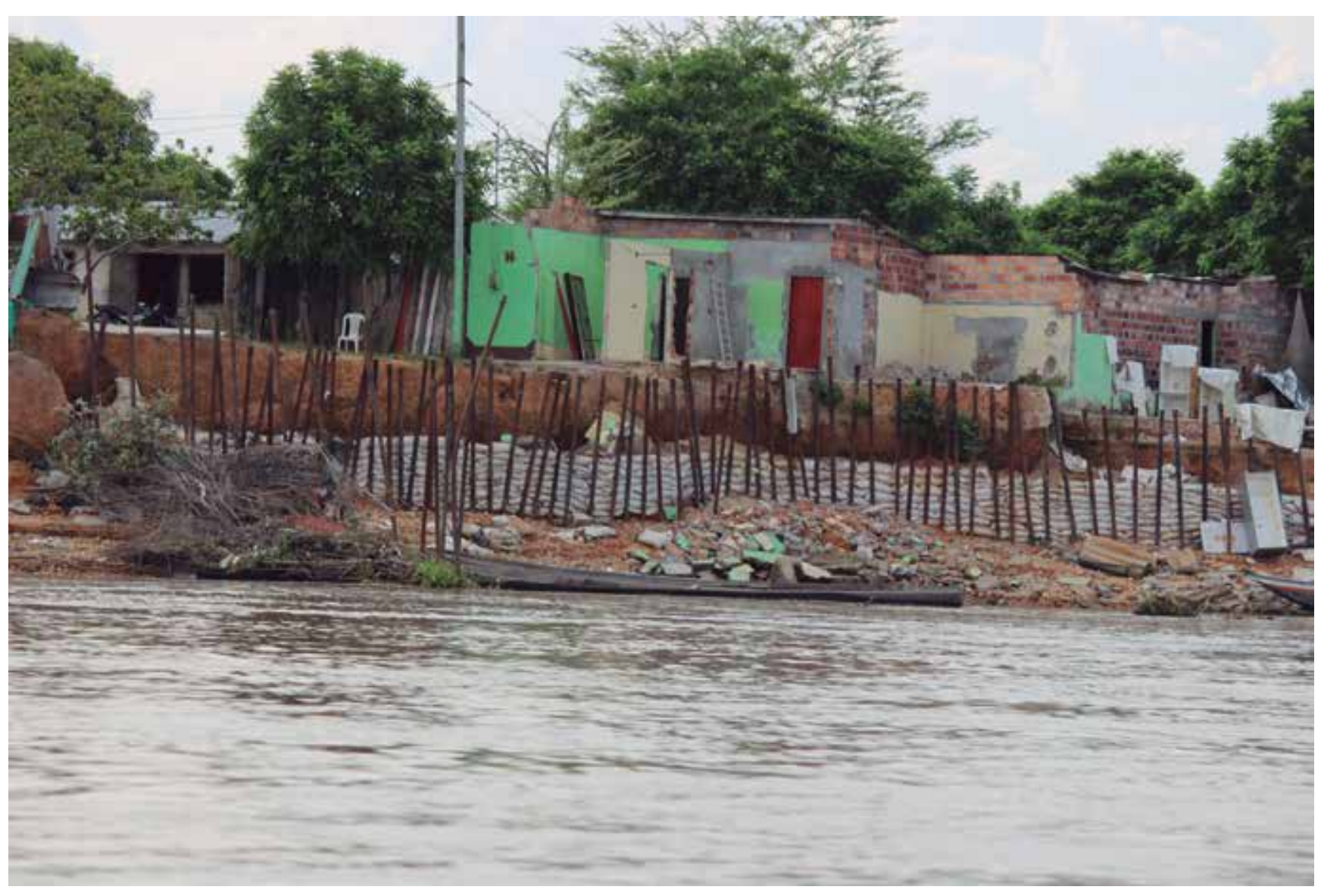

el republicanismo cívico, las democracias posmodernas y la ciudadanía crítica, han sido el eje fundamental de grandes e influyentes tratados sobre el tema y la condición del ciudadano.

Grandes referentes de la ciudadanía, como A. Cortina (2001) en su obra Ciudadanos del mundo; Mouffe (1999) en su texto El retorno de lo político y Bárcena (1997) en El oficio de la ciudadanía, coinciden en que "la ciudadanía comprendida como concepto y práctica de convivencia social es histórica y cultural, pues evoluciona desde determinados enfoques teóricos y valóricos en respuesta a las características del contexto político, social y económico" (Martínez 2010, p. 26). Ese mismo contexto en la actualidad exige un nuevo nivel de evolución, tanto del concepto como de la práctica ciudadana, dicho nivel ha sido determinado por algunos autores como "Ciudadanías emergentes" que "derivan de los nuevos movimientos sociales que ponen de relieve nuevas subjetividades en la conquista de una ciudadanía que explora nuevas dimensiones de la misma" (Alguacil, 2002, p. 2).

Ahora bien, las ciudadanías emergentes derivadas de los movimientos sociales que han surgido en la actualidad en diferentes contextos, se caracterizan por "su complejidad, su diversidad, su permeabilidad y su interés por implicarse en la acción, en la práctica de la ciudadanía" (Alguacil, 2002, p. 3). Esto es posible evidenciarlo en la forma compleja como se han conformado y llevado a cabo las acciones impulsadas por los movimientos sociales más influyentes en la política de los últimos años en Colombia, como la MANE (Mesa Amplia Nacional Estudiantil) que en el 2011 logró tumbar la reforma a la Ley 30 de Educación Superior propuesta por el Gobierno de Juan Manuel Santos, o la asociación de jueces que lideró María del Pilar Arango, que en el 2012 logró tumbar la reforma a la justicia propuesta por el mismo Go- 
bierno a través de una campaña en las redes sociales en contra de los políticos y magistrados que pretendían hacer una reforma a la medida de sus intereses. De la misma manera se puede hacer alusión al movimiento “Dignidad papera o Agropecuaria" que lideró Cesar Pachón en el 2013, movilizando a cientos de campesinos en el paro agrario que sacudió al país entero; y al partido del tomate que inició gracias al inconformismo que la política tradicional dejó a un grupo de jóvenes universitarios que decidieron tirarle tomates descompuestos a las vallas que algunos políticos usaron para hacer campañas en la que manejaban el discurso del miedo e incitaban al odio, como lo relata María Jimena Duzán (2014) en su libro Emputados, el libro de los indignados colombianos.

De la misma forma se pueden mencionar como movimientos sociales de conformación y acción compleja aquellos que dieron origen al fenómeno que cambió significativamente la política del norte de África, y que a través de la primavera árabe y sus protestas lograron tumbar el establecimiento político y cambiar las estructuras de poder de algunos países donde dichas estructuras parecían perpetuarse en el tiempo. Para M. Hardt (2012) “la relación con los movimientos sociales es igualmente muy importante. Muchos gobiernos latinoamericanos -y también el caso de Obama- han llegado al poder navegando sobre la ola de los movimientos sociales" (p. 178).

Para autores como J. Alguacil (2002) "el objetivo de estos nuevos movimientos sociales tiene una doble dirección: particularizar los valores universales y universalizar las identidades particulares" (p. 4) como se observa en los casos citados del contexto colombiano, especialmente en el caso del movimiento dignidad agropecuaria, como lo afirma su líder Cesar Pachón, cuando se refiere a la alianza entre campesinos e indígenas y otros movimientos sociales del país

El objetivo principal es el movimiento social y obviamente eso va de la mano con la parte política porque si no nos metemos en la parte política, si no tomamos decisiones en el país, no influimos, pues van a seguir desconociéndonos (Duzán, 2014, p. 54).

Del esfuerzo realizado por los líderes de estos nuevos movimientos sociales que logran influir de manera significativa en las políticas públicas y en la gobernabilidad de un país, emergen las nuevas formas de ejercer la ciudadanía o de ser ciudadano en un contexto favorable para la génesis de este tipo de movimientos y acciones sociales que son determinantes, en la mayoría de situaciones, para reconstruir o definir el futuro de una sociedad como la nuestra que se encuentra negociando, a través de su Gobierno, la finalización de un conflicto armado que la ha agobiado por más de cincuenta años.

Ahora bien, para que estos movimientos sociales se puedan nutrir de ciudadanos emergentes que logren desarrollar las nuevas dimensiones que la ciudadanía actual le exige, es necesario comprender la ciudadanía como una praxis que resulta del conocimiento, la comunicación y la conciencia, en suma, una praxis que "permite a los ciudadanos el acceso a la acción, a la ciudadanía como práctica. De tal modo que el sujeto solo accede a una ciudadanía plena si es capaz de crear, (re)definir, descubrir y (re) construir derechos, deberes y alternativas" (Alguacil, 2002, p. 4) y facilita su aplicación un Estado que asuma su nuevo rol frente a dos necesidades fundamentales para el surgimiento de las nuevas manifestaciones de la ciudadanía:

la primera, regulando desde abajo e internamente la proyección de una democracia participativa en las diferentes escalas (regionales, municipales, distritos y barrios de grandes ciudades), lo que precisa de apoyo político, apoyo en recursos técnicos y financieros a los entes administrativos de nivel inferior, particularmente a los municipios; y la segunda, contribuyendo a la regulación externa favoreciendo así, la incorporación de sus ciudadanos a la cooperación transnacional y trabajando por la construcción de organizaciones transnacionales democráticas (p. 6). 
Partiendo de lo anterior, y en consonancia con D. Held (1991) y C. Mouffe (1999), es posible afirmar que hoy en día, a diferencia del pasado, los individuos tienen la capacidad de disfrutar de múltiples formas de ser ciudadano o ejercer la ciudadanía. Es decir, en la actualidad es completamente aceptable, en una sociedad como la nuestra, que las personas se asocien a diversas comunidades políticas que afectan de manera inmediata y significativa sus intereses, tanto en el plano regional como en el global, sin que dicha asociación se convierta en impedimento o inhabilidad para pertenecer a otros grupos o asociaciones con intereses distintos a los que inicialmente motivaron su preferencia.

En síntesis, hoy en día es posible declararse liberal o seguidor de dichos principios ideológicos y a su vez defender causas ecológicas o ambientalistas para frenar el impacto generado por el consumismo cosechado por el capitalismo salvaje que nos agobia, o participar activamente de manifestaciones en contra del aborto u otras causas que antes eran netamente defendidas por los adeptos de partidos políticos de corte conservador, sin que dichas participaciones sean excluyentes entre sí o las personas parezcan contradictorias en su pensar y en su obrar.

Retomando el principio de la ciudadanía como una praxis que deriva de "las tres C" Conocimiento, Comunicación y Concienciacomo las denomina Alguacil (2002, p. 4), es pertinente plantear una reforma educativa que le permita al Estado prever y suplir las necesidades en cuanto al ejercicio de las nuevas formas de ciudadanía que se avecinan en una eventual etapa de posconflicto.

Previendo las necesidades futuras que pueden derivar del mencionado acuerdo de paz entre la guerrilla de las FARC y el Gobierno Nacional, es posible intuir que un requisito fundamental, para que los acuerdos que se establezcan en el papel se materialicen en acciones concretas para el beneficio de la sociedad, es la reestructuración del modelo educativo y el tipo de individuo que dicho modelo le exporta a la sociedad colombiana. Si bien es cierto que desde hace algunos años se vienen presentando formas alternativas de participación política y ciudadana como los movimientos de indignados o ecologistas que tanta acogida han tenido en la opinión pública, también es cierto que para lograr la consolidación de estas y otras formas de ciudadanías emergentes es necesario replantear los principios y propósitos del sistema educativo.

También será necesaria la implementación de estrategias que permitan desarrollar el conocimiento o alfabetismo político, o formar "intelectuales" como los define Antonio Negrí, quien afirma que "el intelectual es y sólo puede ser un militante, implicado como una singularidad en medio de otras singularidades, inmerso en un proyecto de búsqueda mutua cuyo fin es la construcción de la multitud" (Negrí, 2012, p. 149) que exija al modelo de enseñanza la incorporación de un análisis más equitativo, reflexivo y crítico de las causas sociales, económicas, culturales, políticas y religiosas que dieron origen a un conflicto violento y sin sentido por más de cincuenta años.

Del mismo modo, la reestructuración educativa deberá apuntar a fortalecer las estrategias y mecanismos que le permiten al ser humano suplir la necesidad natural de la comunicación con los otros. Los procesos de enseñanza-aprendizaje que pretenden un mejor desarrollo de la comunicación entre los individuos están perdiendo una batalla, que antes que conflictiva debería entenderse como una gran oportunidad para lograr dicho fin, pues la mediación de la tecnología y todas sus implicaciones han trasformado de manera significativa la manera como las nuevas generaciones comunican sus pensamientos y formas de comprender la realidad.

Hoy más que nunca se hace necesaria una alianza estratégica entre las formas tradicionales de comunicación y las herramientas tecnológicas para promover el gusto por la lectura y 
la escritura, que a su vez contribuyen a la disminución del analfabetismo político mencionado arriba, y que países referentes en materia de innovación en educación como Finlandia han previsto al pretender acabar con la enseñanza obligatoria del método tradicional de escritura cursiva para educar a sus niños en la escritura a través de teclados Qwerty o mecanografía, que "puede ser más útil en su vida laboral", según afirmó Minna Harmanen, responsable del Instituto Nacional de Educación Finlandés (Recuperado el 09 de diciembre de 2014 de http://www. abc.es/sociedad/20141203/abci-finlandia-educacion-escritura-mano-201412030753.html).

El argumento fuerte es que en la actualidad, tanto niños como adultos, tienen más fácil a la mano un ordenador o un teléfono inteligente para escribir o comunicar sus ideas, que un lápiz y un papel como se ha hecho de manera tradicional al momento de comunicarnos a través de la escritura. Y en cuestiones prácticas, gracias a las redes sociales que están mediadas por herramientas tecnológicas que requieren de la destreza y habilidad para escribir por medio de un teclado, se logró promover el movimiento social que dio origen a la denominada primavera árabe en el norte de África, se impulsó la primera campaña a la presidencia de Barack Obama y en nuestro país, se dio fuerza a los movimientos en contra de la mega-minería en Santander y Norte de Santander y al movimiento que frenó la amañada reforma a la justicia.

En cuanto a la tercera $C$, la conciencia, la educación juega un rol determinante en el despertar de esta para lograr un mayor activismo o participación ciudadana, ya sea por medio de las formas tradicionales o las emergentes. Recordemos que como requisito para el surgir de las nuevas ciudadanías se establece la necesidad de nuevas estructuras en cuanto a los gobiernos locales y las organizaciones sociales; esto con el propósito de generar mayor sintonía y cercanía entre las estructuras y los ciudadanos, y así obtener las condiciones favorables para incorporarlos a procesos de comunicación y deliberación que deriven en una mejor y mayor disposición de transmitirles las habilidades necesarias para moverse en la esfera de la política, como lo afirma Alguacil

Se trata, en definitiva, de un proceso recurrente donde la comunicación, el conocimiento y la reflexividad sobre la acción permiten la adquisición de la (co)responsabilidad social y llevan a la emergencia de la nueva conciencia necesaria para desarrollar las nuevas dimensiones de ciudadanía $(2002$, p. 7).

Es posible generar espacios y condiciones óptimas para lograr que la comunicación y el conocimiento permitan despertar las conciencias de los ciudadanos y su participación política sea más reflexiva y crítica, aun en sus formas más tradicionales como el voto para elegir representantes ante el Estado o en las acciones directas que son propias de las democracias deliberativas. Un ciudadano consciente de la situación de su país, conocedor de las causas de dichos problemas y capaz de comunicar a otros su forma de comprender y por qué no, de solucionar dichas problemáticas, es un ciudadano que tiene las capacidades necesarias para combinar a la vez la protesta y la propuesta, es un ciudadano capaz de comprender que "la diversidad es la fuerza de las nuevas ciudadanías y su expresión es la base de su unidad" (Alguacil, 2002, 15).

Se hace evidente, entonces, la urgencia que tiene la sociedad colombiana de generar a través de las estructuras gubernamentales y sociales los elementos necesarios para optimizar el ambiente y permitir que allí donde hay ciudadanos conscientes, conocedores de los problemas que azotan al país y con capacidad deliberativa para discutirlos y solucionarlos, surjan nuevas formas de relacionarse y participar de las decisiones políticas trascendentales que monopolizan las castas y los partidos políticos afines al Gobierno de turno; estas novedosas formas se manifiestan a través de los movimientos sociales que buscan reivindicar los derechos fundamentales de algunos sectores específicos de la sociedad y requieren que 
emerja una nueva condición del ciudadano o en palabras de María Jimena Duzán:

Hoy, la política real no pasa por los partidos tradicionales sino por otras esferas y ya no la protagonizan los políticos tradicionales sino personas indignadas, desesperadas por la ineficiencia de las políticas del Estado, que no se sienten representadas en el establecimiento político tradicional y que, emputadas, están saliendo a las calles y a las redes sociales a protestar $y$ a pedirles cuentas a los que nos gobiernan (Duzán, 2014, p. 16).

Esa nueva praxis de la ciudadanía tiene como principal objetivo la (re)construcción de los pilares esenciales de una sociedad que se ha visto afectada por el flagelo de la violencia y requiere de múltiples acciones pedagógicas que le permitan comprender las distintas dimensiones, causas y consecuencias del conflicto que se pretende acabar. Por ende, se insiste en la necesidad de reformular el modelo educativo y enfocarlo en el desarrollo de las tres " $\mathrm{C}$ " que se mencionan antes, esto con el fin de generar ciudadanos más dispuestos y activos en la reconstrucción del tejido social por medio de procesos de democratización que se esfuerzan por crear estructuras de redes horizontales y participativas. De esta suerte, "las revueltas contra el sistema político dominante, sus políticos profesionales y sus estructuras ilegítimas de representación no aspiran a restaurar un supuesto sistema representativo legítimo del pasado, sino a experimentar con nuevas formas de expresión democrática: una democracia real ya", como lo afirman Hardt y Negri $(2011$, p. 7).

Es imperante una ciudadanía emergente en Colombia que comprometa al Estado a conceder los espacios y las disposiciones necesarias para generar los cambios y transformaciones esenciales para el éxito del posconflicto, recordemos que el conflicto se origina por las casi nulas opciones de participación política que en otrora tuvieron aquellos que hoy empuñan armas para defender sus intereses y dichas opciones deberán ser reivindicadas y puestas a disposición de los ciudadanos que se compro- metan con la construcción de un mejor futuro, porque como afirma el líder campesino Cesar Pachón:

Buena parte del pueblo colombiano no está interesada en saber qué pasa en el país o cómo se solucionan los problemas porque está dedicada a sus problemas, a pensar que no tiene plata, a su vida cotidiana. Por eso este país sigue eligiendo tan mal. Si la gente pudiera salir de sus dramas cotidianos, podría llegar a la conclusión de que la causa de la crisis que uno padece es que este es un país mal gobernado, mal dirigido, que toma malas decisiones y la cosa sería diferente (Duzán, 2014, p. 61).

De esta forma, los ciudadanos por medio de la educación serán capaces de reconocer el origen, el conflicto y el posconflicto, así como sus actores y responsables para reflexionar o despertar su conciencia y superar las épocas de mutuas acusaciones incipientes para darle paso a la era de las protestas que trasciendan a propuestas y una añorada reconciliación, mientras que, como afirma M. Duzán (p. 17), las clases políticas tradicionales anquilosadas ven pasar por sus balcones la verdadera política y cuando se percaten de que el tren las está dejando, van a ser los primeros sorprendidos cuando vean el poder y la fortaleza que tendrán las ciudadanías emergentes.

\section{Conclusiones}

Mientras en Colombia el conflicto armado se entretejió y complejizó con narcotráfico, corrupción, cultura de la ilegalidad, delincuencia común, pobreza extrema, abandono del Estado en áreas tan decisivas como la educación y la salud, se llega a este momento histórico donde el Gobierno, las Farc, y el Eln adelantan diálogos de paz para encontrar una salida negociada y pacífica a la guerra que se libra por más de cinco décadas. Por ello urge que desde la academia se aporten propuestas reflexivas para ayudar a pensar la nueva cultura de la paz y dinamizar la situación de posconflicto, desde las herramientas y riquezas pedagógicas, desde la re-significación de la vida 
como valor sublime, desde el reconocimiento e inclusión de los otros y sus diferencias, en pro de una sociedad viable, posible, para promover la cultura de la vida y de la convivencia respetuosa, para sanar los odios y rencores que dejó más de medio siglo de violencia.

Desde el marco teórico propuesto, donde se contempla la pluralidad de las violencias y la polifacética condición humana, es evidente que los actores del conflicto no se reducen a los grupos armados -que están al margen de la ley enfrentados con la fuerza pública- quizá todos estamos involucrados en esta cultura de la violencia que se incubó en la sociedad colombiana y tiene sus orígenes en la condición humana y en la influencia que dicha condición recibe del entorno sociocultural. Lo que se necesita es evidenciar dicha situación para ayudar a pensar otra sociedad posible, desde una cultura que respete, valore, defienda y cuide la Vida. Porque los habitantes de esta tierra merecemos vivir más de cien años de esperanza y libertad.

\section{Referencias}

Alguacil, J. (2002). La ciudadanía emergente y sus síntomas. Recuperado de http://habitat.aq.upm.es/boletin/n24/ ajalg.html

Arendt, H. (1998). La condición humana. Barcelona: Paidós.

Bárcena, F. (1997). El oficio de la ciudadanía. Barcelona: Paidós Ibérica.

Bhagwan. (1995). Vida, amor, risa. Medellín: Editorial Endymion.

Bonilla, Cardona, y Rodríguez. (2015). Pensar la ciudadanía: condición humana y democracia. Bucaramanga: Ediciones USTA.

Claux, I., Esguerra, L. (2011). La búsqueda. Bogotá: Aguilar.

Constitución Política de Colombia de 1991.

Cortina, A. (2001). Ciudadanos del mundo. Hacia una teoría de la ciudadanía. Alianza, Madrid.

Cruz, E. (2013). Los monstruos en Colombia sí existen. Bogotá: Grijalbo.
Diario virtual ABC.es Disponible en http://www.abc.es/sociedad/20141203/abci-finlandia-educacion-escrituramano-201412030753.html

Duzán, M. J. (2014). Emputados, el libro de los indignados colombianos. Bogotá: Planeta.

Freire, P. (2007). Pedagogía de la esperanza. México: Siglo Veintiuno Editores.

Fromm, E. (1966). La revolución de la esperanza. México: Fondo de Cultura Económica.

Hardt, M. (2012). Pensar desde la izquierda, mapa del pensamiento crítico para un tiempo de crisis. Errata naturae. Madrid.

Hardt, M., y Negri, A. (2011). Commonwealth. El proyecto de una revolución del común. Madrid: Akal.

Harmanen, M. (2014). Instituto Nacional de Educación Finlandés. Recuperado el 09 de diciembre de http://www. abc.es/sociedad/20141203/abci-finlandia-educacionescritura-mano-201412030753.html.

Held, D. (1991). Modelos de democracia. Madrid: Alianza.

Martínez, L. et al. (2010). ¿En qué ciudadanía creen los jóvenes? Creencias, aspiraciones de ciudadanía y motivaciones para la participación sociopolítica. Revista PSYKHE, 19(2), 25-37. ISSN 0717-0297.

Mejía, M. R. (2006). Educación (es) en la (s) globalización (es) l. Entre el pensamiento único y la nueva crítica. Bogotá: Ediciones Desde abajo.

Instituto Colombiano para el Fomento de la Educación Superior - ICFES. (2001). Memorias (t. II). Primer Congreso Internacional de Pensamiento Complejo. Bogotá, 8, 9 y 10 de noviembre de 2000. Bogotá, D.C.

Mendoza, M. (2014). Paranormal Colombia. Al filo de lo real. Bogotá: Editorial Planeta.

Mockus, A. (1999). Educación para la paz: una pedagogía para consolidar la democracia social y participativa. Bogotá: Editorial Magisterio.

Morin, E. (2011). La Vía: para el futuro de la humanidad. Barcelona: Paidós.

Morin, E. (2001). Los siete saberes necesarios para la educación del futuro. Colección Mesa Redonda, 88. Bogotá: Cooperativa Editorial Magisterio.

Mouffe, C. (1999). El retorno de lo político. Barcelona: Paidós.

Negrí, A. (2012). Pensar desde la izquierda, mapa del pensamiento crítico para un tiempo de crisis. Errata naturae. Madrid.

Nussbaum, M. (2014). Emociones políticas. ¿Por qué el amor es importante para la justicia? Barcelona: Paidós.

Ospina, W. (2013). Pa que se acabe la vaina. Bogotá: Planeta. 